\title{
Streams, Grants and Pools: Stakeholding, Asset-Based Welfare and Convertibility
}

\section{Introduction}

Many recent policy debates have centred on the possibility of constructing post-social insurance and post-means tested forms of income provision. Advocates of a Basic Income (BI) fall under this heading (Fitzpatrick, 1999; Van Parijs, 1995, 2003). Discussion has also concerned 'Capital Grants' (CGs) which would provide an endowment designed to improve the assets to which individuals have access, such as the UK's Child Trust Fund. Such CGs have been referred to as 'stakeholder welfare' and 'asset-based welfare' (LeGrand, 2003, Ch.9; Nissan \& LeGrand, 2000), though this article proposes that such headings apply to both CGs and BI as the differences between them are often overstated.

The article has two objectives. Firstly, having justified that proposition, by identifying the key similarities and differences between CGs and BI, it makes a case for an unconditional, non-time-limited and partial BI. Secondly, the article reviews the issue of convertibility, i.e. the main normative questions to consider when designing a system permitting the mortgaging of streams into what I here call 'pools'. I am not going to discuss stakeholding and assetbased welfare at a conceptual level, treating these simply as entitlements to a stock of social resources from which a personal capital fund can be derived over which individuals have some measure of control and which is intended to enhance their wealth and income.

\section{Three Sites}

I want to begin with two spectra. The first concerns streams and grants. A stream consists of an income or dividend that is received on a regular and frequent basis, usually measured in weeks or months, over a long time period. If a BI is designed as a weekly or monthly income then it is a stream. A grant will typically provide a one-off payment, although some versions propose distributing the grant in regular but finite instalments over several years (Ackerman \& Alstott, 1999).

There are various reasons why a stream may be preferred to a grant. Firstly, it protects you from yourself. By spreading a person's entitlement over a long period of time they are prevented from blowing this resource ('stakeblowing') through recklessness. Secondly, it is more of an insurance against external shocks. Even when acting with reasonable foresight individuals cannot anticipate all of circumstances that may affect their lives. A stream is therefore a safety-net which can reasonably be anticipated to stretch into the future. Finally, so long as that guarantee is ensured a stream places more control in the hands of government in dealing with changing circumstances. For instance, when aggregate spending is low the stream can be modified as a form of demand management.

There are, conversely, several reasons why grants may be preferred to streams. Firstly, grants typically offer sizeable sums that can be assist lifetime-changing events, e.g. to help buy a house, fund educational 
qualifications, or assist business start-ups. Secondly, grants are attractive to some because they emphasise the responsibilities of individuals. Finally, streams are arguably insensitive to brute luck and to class-based inequalities in longevity. When someone dies young, whether as a result of an accident or unjust social disadvantages, they forgo much of the entitlement that would have been theirs had they been luckier or socially more privileged. Whereas if a grant is provided early in life then all but the unluckiest (those who die very young) will be able to employ the endowment to some extent.

Proponents of both sides have counter-arguments to the above (Wright, 2006). Against the arguments for streams advocates of grants can insist that freedom demands that individuals be armed not only with resources but with the duty to invest those resources maturely. If there are unforeseen shocks and circumstances ahead then people should factor this into their investment strategies, but if they misuse their endowment then tough. Furthermore, the argument about demand management identifies a stream as a government bequest rather than a right of citizenship. If governments need to act they should not do so by manipulating our basic entitlements.

Advocates of streams also challenge the advantages claimed for grants. Perhaps we ought to recognise the limits to autonomy, for instance. If individuals can be treated as free and responsible but as often lacking the information and/or will to use their freedom and responsibility effectively then autonomy may be perfectly compatible with paternalism (Goodin, 2002). Furthermore, arguments about brute luck and inequality are potentially misplaced. Spreading entitlements out, instead of concentrating them in lumpsum form, recognises that brute luck is an enduring feature of human life and avoids the harsher implications of luck egalitarianism whereby option luck comes to dominate distributive criteria (White, 2007, pp. 92-5). And while class inequalities of longevity are worrying, income streams can be designed to compensate for these, e.g. by allowing those from disadvantaged backgrounds to draw their pension income earlier.

My purpose so far has been to suggest that much of the disagreement above - and we revisit some of these arguments in greater depth below - revolves around the meaning of concepts such as freedom/autonomy and security/paternalism. This is my second spectrum and one I want to pursue by exploring at greater length some of the main positions that have been taken vis-à-vis streams and grants. It should be noted that much of the sound and fury originally accompanying the above debates has faded, without disappearing entirely (de Wispelaere \& Stirton, 2004, p. 270). The most famous exponent of BI has said that,

There is a significant difference between a regular basic income and such a basic endowment. Yet it should not be overstated. (Van Parijs, 2004, p. 9) ${ }^{1}$

And one of the earliest advocates of asset-based welfare summarises why:

In their most unrestricted forms, the two ideas of a basic demogrant and a basic income are very similar, for, if capital markets were perfect, one

\footnotetext{
${ }^{1}$ Van Parijs (2006, p. 204) opposes the full conversion of BI into a grant but does not seem to have ruled out the partial convertability argued for below.
} 
could be readily converted into the other. Thus a demogrant can be used to purchase an annuity, thus generating an income for life; and a basic income can be mortgaged or borrowed against, thus creating a capital sum available for immediate use. (LeGrand, 2003, p. 123)

Despite this rapprochement the debate continues to reveal some strong differences of opinion. So while I want to examine the issue of convertibility later we first have to appreciate (a) why advocates of streams and grants form a broad consensus, but also (b) why there can never be complete unanimity. I shall therefore cross-reference the above as in Figure $1 .{ }^{2}$

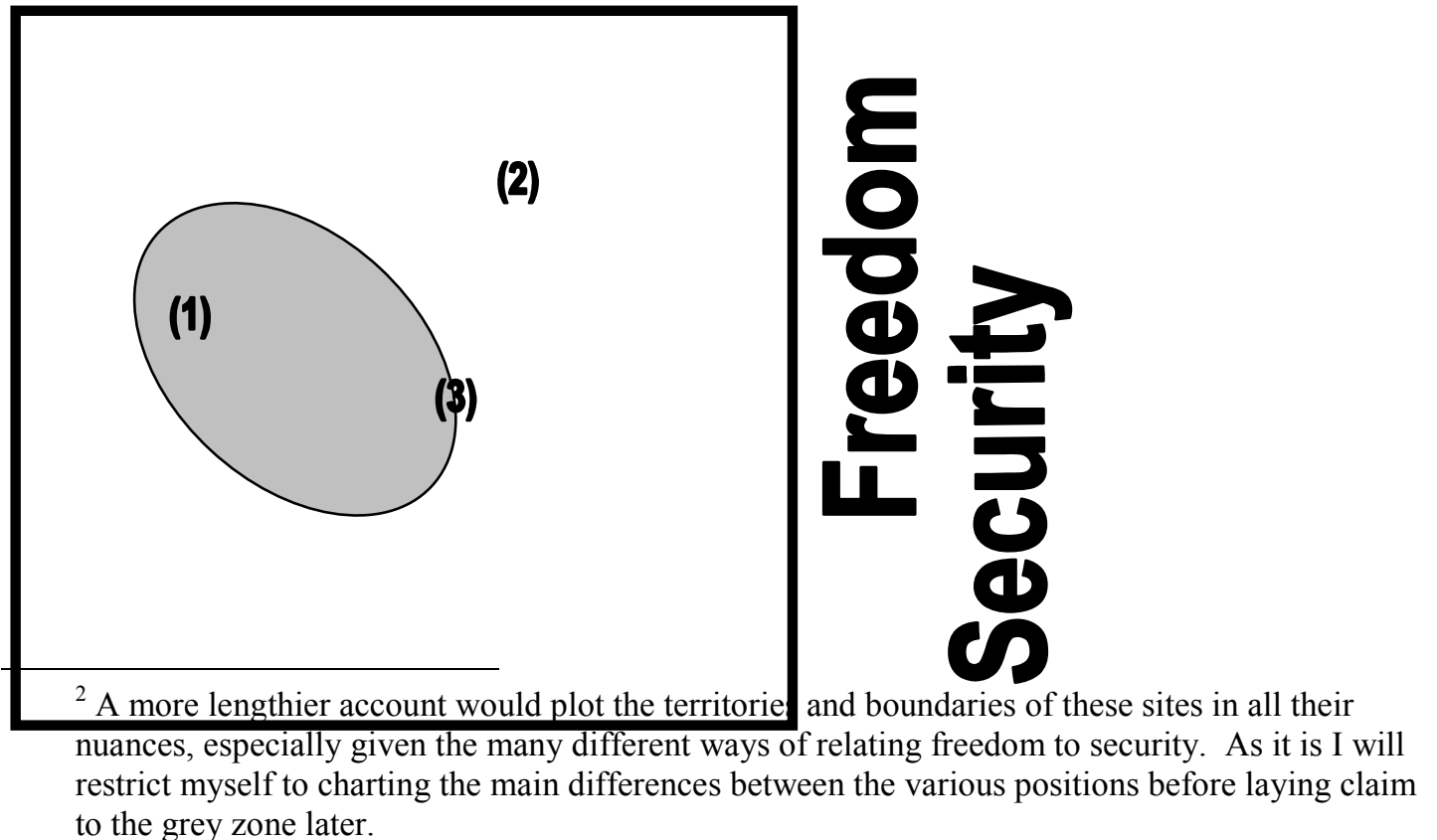




\section{Streams \\ Grants}

\section{Figure 1 \\ Connecting Streams and Grants}

\section{Sites $1 \& 2$}

Let us take site (1) first. This zone is occupied by those who defend streams as the best way of maximizing freedom (Beck, 2000, Ch.8). Van Parijs, for example, assumes a universal and lifelong desire for people to protect their 'real freedom' at older ages against weaknesses of the will at younger ones:

... a mildly paternalistic concern for people's real freedom throughout their lives, not just 'at the start', makes it sensible to hand out the basic income in the form of a (non-mortgageable) regular stream...(Van Parijs, 1995, p. 47)

Real freedom across the life-cycle is therefore maximized by incorporating mild paternalism into our scheme based upon an assumption that people desire protection but cannot be entirely relied upon to protect themselves because of possible weaknesses of will.

From a feminist perspective Pateman (2004) argues that a gender-sensitive liberalism has to appreciate how the interdependencies of households and labour markets are currently allocated unequally and unfairly between men and women. Streams, she says, are not only superior because they make people less vulnerable to vicissitudes and market circumstances but also because by taking the emphasis away from paid work BI challenges masculinist assumptions about what it is to make a social contribution and to free-ride. One difference between Van Parijs (1995, p. 48) and Pateman (2004, p. 95) is that the former allows for the possibility, to be judged on pragmatic grounds, for lengthening the frequency of the income stream and so converting a BI into a quasi-CG, while the latter resists CGs per se because she fears they could not be relied upon to change patriarchal behaviour over the long term.

What criticisms might be made of site (1)? One question concerns what Van Parijs means by mildly paternalistic. Though we may blanch at handing out the full endowment 'at the start' of someone's adult life this does not necessarily imply that it must then be distributed equally throughout the rest of that person's life. Because it seems reasonable to assume that people can, on average, exercise greater self-control and self-awareness in their $30 \mathrm{~s}$ and $40 \mathrm{~s}$ than they can in their teens or 20 s then why not weight an endowment's 
distribution to those decades when recipients have the need and the ability to make greatest use of it? Now, as indicated above, Van Parijs does not rule converting the stream into a grant but labels this a matter of 'pragmatic compromise'. Yet this feels like an absence of principle. What rules should guide convertibility? The opportunity to convert $80 \%$ of a given sum into a one-off endowment is based upon a weighting of freedom and security different from the opportunity to convert just $20 \%$. This is not to claim that Van Parijs' 'real libertarianism' cannot yield such principles but to observe that, to my knowledge, it has not yet done so.

The problem with Pateman's defence of streams is that it is perhaps too defensive. Advocates of CGs argue that their desire is not to leave long periods of citizens' lives to the vagaries of chance but that CGs are more capable of bringing circumstances under control by allowing the individuals concerned to decide how and when to negotiate life's main events (Ackerman $\&$ Alstott, 2004). In addition, Pateman (2004, pp. 100-01) argues that a BI would be more gender-friendly than CGs by advocating a full BI, i.e. one providing enough to live on without the need for supplements, but if this is an unrealistic expectation for the foreseeable future then, in addition to the other reforms which she also acknowledges as necessary, might women not gain by having available to them an endowment which gives an enormous (albeit oneoff) boost to their financial independence?

Should we look elsewhere, then, for a better way of reconciling streams and grants, freedom and security? What about site (2)? Ackerman and Alstott (hereafter 'A\&A') proposed in 1999 that each individual should receive $\$ 80 \mathrm{~K}$ after reaching the age of 21 so long as they possess a high school diploma and stay clear of crime. The money would be distributed in four yearly instalments, rather than all at once, to encourage reflection upon how the money might be spent, but once received there would be no restrictions on its use. They provide three main reasons why such a citizen's stake would be better than a BI (Ackerman and Alstott, 1999, pp. 210-6).

Firstly, that it is easier to imagine the stakeholder converting their grant to a monthly income, by buying an annuity from an insurance company, than to envisage converting BI into a grant. This is because if it is to guarantee future income the BI must remain immune from any future creditors in the event of bankruptcy, whilst the CG would have to be surrendered in order for any debts to be paid. The BI therefore has the government potentially underwriting an adult's irresponsibility. Secondly, they argue BI is an unwarranted "restraint on alienation" (Ackerman and Alstott, 2004, p. 45), i.e. on the possibility that the grant could be lost through reckless behaviour. It may be bad for the individual if they blow their $\$ 80 \mathrm{~K}$ at the casino but not necessarily worse for society if they have been thereby treated as responsible adults. Finally, BI embodies a kind of temporal inefficacy. By having a given sum doled out in small increments the BI encourages short-term consumerism whereas the $\mathrm{CG}$ requires recipients to think of their lives long-term; plus, as mentioned above, a BI is potentially unfair to those who die very young.

That said, Ackerman and Alstott (1999, Ch.8) do not wish to leave the reckless or unlucky completely to their own devises; the exhaustion of the $\mathrm{CG}$ should not engender the collapse of every welfare entitlement. This is particularly the case with the elderly and so they propose that all above the age 
of 67 would be entitled to a citizen's pension. Their system of stakeholding therefore incorporates CGs plus age-related income streams.

Is this persuasive, though? Defenders of streams are entitled to claim the following. Firstly, Ackerman and Alstott (2004, pp. 47-8) are quite selective when invoking responsibility. Blowing your stake in Las Vegas is taken as a sign of responsibility while going to loan sharks (in order to convert your BI to a lump-sum) is not. A\&A are entitled to object to the state protecting you in full from your irresponsibility but this is not what a BI system would necessarily do. The state would not absolve you of your debts it would simply place limits (as it already does) on the assets and entitlements that can be seized for the purposes of debt repayment. This is less a restraint on alienation per se and more a restraint on the complete alienation of one's entitlements. For although it arguably improves social responsibility their CGs also risk encouraging a culture of neglect towards those seen to have wasted their chances, giving too much prominence to option luck. ${ }^{3}$

Secondly, therefore, in their 'restraint' argument A\&A largely bypass the egalitarian debate about desert and undeserved circumstances (Arneson, 2003; White, 2007, Ch.4; cf. Ackerman, 2003). Put crudely, this debate indicates that whereas we can be held responsible for those circumstances over which we possess control we cannot for those over which we have no or minimal control. Opinions differ but by and large egalitarians agree (a) the concept of freedom cannot provide a full account of human being and social agency since some circumstances will always be at least partially beyond individual control, and (b) that those limits are especially constraining in a capitalist society, particularly for the least advantaged. Now, their CG would deliver considerable assets to the poorest but by associating it so closely with the principle of equal opportunities, while demonstrating hostility to the concept of 'outcome equality' (Ackerman and Alstott, 1999, pp. 97-100; Ackerman, 2003, pp. 181-7), they might be accused of either neglecting undeserved circumstances or underestimating the measures needed to address them. By contrast, an egalitarian defense of BI views it as one element of a much wider, long-term and more radical challenge to the inegalitarian trends of recent decades, one that emphasises the recurring needs for guaranteed safety-nets and for parity in the distribution of primary resources (Fabre, 2003). So, with A\&A having already readmitted income streams into their CG scheme BI advocates are entitled to argue for an even greater role.

Site 3

What about site (3)? Whereas A\&A's scheme is ultimately something of a hybrid so too is White's (2004) who offers more of a balance between freedom and security. He agrees with the advocates of streams that a pure $\mathrm{CG}$ scheme would be too insecure, inviting people to spend the money recklessly by either blowing it or using it for purposes that are socially harmful. However, this does not rule out CGs completely so long as two paternalistic conditions are met. The first is that those receiving it also receive education in

\footnotetext{
${ }^{3}$ One referee noted that A\&A would leave us to bear the burdens of our poor choices in the shortterm but not the long (hence their support for a citizen's pension). In principle this sounds acceptable but advocates of streams maintain that A\&A's preferred balance between, and perhaps even definition of, long- and short-term is not paternalistic enough.
} 
the management of assets, so offsetting the possibility that those from poorer backgrounds will use their grants less effectively than those from more affluent ones. The second condition is to reduce the opportunity for stakeblowing. This might mean opting for a pure BI system but White (2003a, 2003b) has long believed that this would violate the principle of fair reciprocity (cf. Fitzpatrick, 2005). His hybrid scheme would therefore involve, firstly, limiting the range of activities for which CGs could be used to a 'development grant' that could be spent on education, training or business investment. However, allowing for the possibility of,

...situations in which we may be particularly vulnerable, emotionally and often economically, and so at a particular risk of dependency. (White, 2004, p. 72)

White, secondly, advocates attaching those development grants to an unconditional but time-limited BI. The latter would be available without the need for a means-test or work-test but for a fixed maximum number of years (between 2 and 5, he suggests).

White's defence of liberal freedoms is therefore tempered to principles of responsibility and paternalism that makes room for both grants and streams. Therefore, while he exemplifies site (3) he also reaches out to (1) and (2) by acknowledging the relevance of freedom-based arguments so long as these do not invite new forms of social exclusion and irresponsibility. Does this, then, represent the consensus that I mentioned earlier and for which we should be seeking? Possibly, but there are four potential problems with White's position.

The first is that, as White (2004, p. 73) acknowledges, his development grant would be costly to administer. Since it could only be used for specific investment purposes individuals have to apply for it and have their applications either approved or turned down (with an additional process to deal with the many appeals the latter would no doubt generate). If it is to be rigorous this means instituting a large and complex bureaucracy since in a country like the UK the number of applications per year may number in the millions.

White, though, considers this complexity a price worth paying for two reasons. ${ }^{4}$ He proposes that such bureaucracy may provide the insurance against stakeblowing which he regards as important paternalistically. However, the persuasiveness of this counter-argument presumably depends upon how 'loose' or 'tight' the application procedure is. If the application process consists only of formalities, where one can pay lip-service to the officially-sanctioned investment activities, after which it is possible to 'take the money and run', then such formalities are obviously open to abuse. By contrast, if I borrow money from a bank for a training course and then waste it on horseraces I still owe the bank money. So should there be an equivalent with the development grant? Should I have to prove (if so, how and how

\footnotetext{
${ }^{4}$ A third possible counter-argument is that such complexity would be obviously reduced if the development grant replaces some or all of those asset-entitlements that currently relate to higher education applications, bank loans, home loans, etc. However, I have not found White making this point since the development grant is presumably intended to supplement, not replace, these other entitlements.
} 
many times?) that I have used the grant as originally claimed? Should the state be able to reclaim the stake if I have in any way defaulted? This 'tighter', more rigorous system would minimise the possibility of abuse but only by once again increasing bureaucratic complexity and cost. White considers these to be a price worth paying but by ring-fencing his development grants so tightly we are entitled to wonder whether these are little more than reformulated student, home and business loans; a welcome advance, no doubt, but perhaps not quite the radical break with current practices that we might hope for. ${ }^{5}$

White's other counter-argument is that if a development grant has economic benefits, e.g. lowers unemployment, then the level of the stake can be raised and, again, the price of complexity is worth paying. But this leads on to a second criticism of White's proposal, one regarding the type of activities to be funded. Take education. If the development grant is intended to make sure that everyone makes a social contribution then applicants, as now, could apply for a BA in Ancient Greek on the grounds that society gains from having someone who knows the language and culture of ancient Greece. However, by citing an 'economic benefits' argument, White allows the vocabulary of social contribution to slide into that of productive contributions. If the development grant is regarded as society's investment in its human capital then presumably we should either not fund degrees in Ancient Greek or at least give such applicants far less those applying for a BA in Business Administration. In short if we ring-fence the grant too tightly around the principle of productive investments then we risk omitting a range of valuable (but not necessarily productive) activities. This would make reciprocity resemble a marketised contract where the value of the 'repayments' must approximate to the 'loan' bestowed; a tit-for-tat conception of reciprocity that potentially misses the extent to which social participation is and should be more diverse than this. If, therefore, we then loosen the fence to avoid this critique then White's 'economic benefits' argument falters and we move back towards a development grant scheme consisting merely of formalities.

In short, by interpreting society as a cooperative assemblage of benefits and burdens White risks committing the mistake identified by Nussbaum (2006, pp. 118-9) of equating 'social cooperation' with 'productive contribution' and so of continuing to exclude those activities and forms of membership which do not correspond to this contractualist model. White (2003a, pp. 112-3) is receptive to the ethic of care, for instance, but only to those caring activities which perform a 'significant service' to others. Yet there can be a spectrum of 'significance'. Benefits for primary carers are justified (and would presumably be needed under a partial BI scheme) but the point of BI is to help decommodify social relations and so excavate spaces through which nonmonetary values can breath more readily than at present. This leaves open the big question of how to encourage ethically valuable behaviour, for surely that 'space' would also be used by those possessing an 'ethic of carelessness'. This is partly why I prefer a partial BI below, but it should also be observed

\footnotetext{
${ }^{5}$ Admittedly, the freedom-enhancing effects of a development grant will depend upon the socioeconomic context, which is why I make potentially allow room for it later as a pragmatic and transitional measure. But the advantage of an unconditional, non-time-limited BI is that it could more usefully assist the shift towards an alternative socioeconomic context, hence my scepticism about the long-term radicalism of development grants.
} 
that responsibility requires an 'agora' of trust and openness. This is surely the case unless we are to regard moral values as so fragile and moral agents as so imperfect that people must be treated as self-interested, economic actors who should be straightjacketed by systems of dis/incentives.

My third criticism concerns the 'paternalist turn' White favours. He argues, contra A\&A, that paternalism has to be a feature of CGs but that, contra Van Parijs, a non-time-limited BI violates notions of fair reciprocity. This is his ground for preferring a conditional CG. Now, I have addressed his argument vis-à-vis BI's unconditionality principle elsewhere (Fitzpatrick, 2005), a proper summary of which would take too long here, except to say the following. White and his co-authors claims that BI advocates are being inconsistent by arguing (a) that we should provide an income stream to protect people from the bad judgements a lump-sum payment might invite, and (b) that this should be provided unconditionally (Dowding et al, 2003, p. 27). The inconsistency is that (a) is an argument from paternalism and (b) an argument against it. Therefore, why not just admit that any stakeholder scheme has to have conditions attached to it?

Here, Dowding et al are certainly correct to identify an inherent problem with the concept of unconditionality, that it presents itself as such an all-ornothing principle. Few if any BI advocates would embrace unconditionality per se since this would, for instance, involve providing BI to convicted murderers. But once we admit the clumsiness of the term the above argument of Dowding et al about inconsistency becomes less relevant. The reason why 'unconditionality' is worth retaining, despite its clumsiness, is because BI defenders want a presumption in its favour. Analogous to the case where universalist provision can still imply targeting and selectivism, unconditionality is a principle worth defending even when we qualify it and chip away at its outer edges. BI advocates are therefore entitled to treat unconditionality as consistent with paternalism, albeit with implications about which Dowding et al no doubt disagree.

Finally, we can object to White's time-limiting of BI. His argument is that because a development grant might be exhausted, but its recipient still requires help, then an additional time-limited BI is justifiable. But White frames his defense of this limited BI in terms of "emergency needs" (White, 2004, p. 72), "crisis and transition" and "financial independence in periods of difficulty which might otherwise expose them to dependency" (White, 2003b, p. 91). Now, this safety-net aspect is certainly important and prevalent within the BI literature, yet the latter also goes beyond such negative reasons to more positive ones. Take the following example, based upon the kind of liberal communitarianism White favours.

Walzer (2004, pp. 19-20) observes that associations have both involuntary and voluntary elements. Exit is possible even from the most involuntary associations (nations, families) though the cost of doing so is usually high; meanwhile, the cost of leaving all but the most trivial voluntary associations is never zero. The implication is that freedom is (a) always limited but (b) also relative to the degree of mobility we experience. Those who command and mobilise the greatest resources possess the highest level of mobility in that they are able to minimize the costs and maximize the benefits of either staying or going; also, their greater power of exit confers upon them the loudest voice since groupings have much to lose from their absconding and so an incentive 
to lavish influence and power upon them. How should social democrats respond to this state of affairs, these inequalities of exit/voice? Typically, they do so by proposing to address inequalities within associations, address inequalities between them and by equalizing opportunities for mobility:

The more that men and women are free to move and the more groups there are to which they can escape, the more difficult it is to maintain either subjection or hierarchy. (Walzer, 2004, p. 75)

Walzer's point is not that we must be constantly moving from group to group, more that the opportunities for exit from and voice within associations should be equalized to the greatest extent possible. It is in this context that a possible case for making a minimum income an unconditional income can be made.

The basic argument is that the more conditional a minimum income is then the more it risks becoming conditional upon the very set of relationships a person is trying to exit from. Now a degree of conditionality is desirable if the formation of and entry into associations is not to become facile and disposable. The fact that some may wish to exit an association does not automatically mean they should be allowed to do so. If family relationships are to be meaningful and durable then its members must know in advance that separating themselves from it makes some costs inevitable. Conversely, though, if those costs are too high then the family risks resembling a prison. Exits from most associations must therefore be neither wide open nor locked. Would an unconditional income help to achieve this balance? Supporters argue that it would make exits more available to those with the fewest resources, not simply through the amount of money it provides but because it can be accessed quickly and is not tied to eligibility-criteria, i.e. remains within the control of the individual herself (Wright, 2004). This, though, does not mean that an unconditional income would lower costs to zero since a full exit may depend upon severing links that are association-relative. The point is that unconditionality offers more power to individuals by making exits less restrictive (Goodin, 1992).

Now, White will accept this argument up to a point but would no doubt observe that since all associations occupy the same social space, and since this space depends upon a minimum of social cooperation, then the performance of certain non-negotiable activities is violated by a non-time-limited BI. In other words, the one association we cannot exit is society and therefore a 'civic minimum' of social cooperation is required as the sine qua non of citizenship; a minimum that an unconditional, non-time-limited BI would not guarantee.

The counter-argument is threefold. Firstly, the time-limitedness White favours makes exits less possible beyond a certain point despite that fact that we are prone to relationship breakdown, bereavement, changes in jobs, careers, location, beliefs, etc. throughout our lives. ${ }^{6}$ Because important lifeevents cannot be time-limited then any time-limited income maintenance system risks unfairness and injustice. Secondly, then, and according to the view advanced by Walzer above, by reducing our mobility a time-limited BI also reduces our voice and might make subjection and hierarchy more likely.

\footnotetext{
${ }^{6}$ Obviously, much depends upon the length of White's time-limited BI. The longer it is then the less effective this criticism becomes but this would presumably decrease the resources available for the development grant it was meant to supplement.
} 
Thirdly, BI recognises our shared social space if it is unconditional, non-timelimited but also partial, i.e. needing to be supplemented by other income sources, since the latter stipulation makes it less likely that people will become socially detached for any substantial length of time. ${ }^{7}$ This latter version of BI therefore offers safety-nets but also a lifelong resource through which participation in associations can be strengthened by granting people improved rights of exit from them, but rights that do not allow permanent detachment from social cooperation per se. Therefore, even if we remain within a liberal communitarian framework we can see that there are positive reasons for favouring BI that take us beyond the time-limitedness which White prefers.

In this section I have sought to underline the commonalities between the above zones: Van Parijs does not rule out some role for grants (see footnote 1); A\&A make room for a citizen's pension; White is attracted to a (timelimited) BI which accompanies a system of development grants. Both streams and grants, BIs and CGs, are opposed to extensive means-testing and to social insurance benefits based heavily around paid work. Both define citizens as stakeholders rather than primarily as clients and employees; and both agree we should systematise and coordinate the lifetime assets and endowments to which we already have access while also seeking to extend and improve these in some way.

Important differences between them exist, however, over and above the obvious disagreements about how frequently the lifetime stake or asset should be provided; and although the exponents of each site reaches out to the others no consensus exists. Indeed, Van der Veen (2003, pp. 163-6) contends that BI and CGs imply two different cultures: the former is a culture of disposable time where, because they face fewer financial constraints, individuals acquire more freedom to choose alternative mixtures of productivist, informal and leisure-based activities; the latter does not exclude such time-autonomy but is based upon a culture of property ownership, market independence and entrepreneurship in which people become mini-investors within the capitalist game. Of course, given the practicalities and compromises required in an imperfect world, and given the real divergences between the principles of freedom and security, it is reasonable to doubt that a consensus ever could exist. This does not mean a shift towards asset-based and stakeholder welfare could not transpire, simply that it would be subject to the same disputes and negotiations to which means-tested and social insurance systems are subject.

My own preference, bordered by the grey area in Figure 1, is for a defence of streams that draws upon site (1) - and to a lesser extent site (3) - on the grounds that streams offer greater long-term freedom and security than grants, in terms of exit and voice, income and time (Fitzpatrick, 2005). However, this does not mean that the advantages of grants should be ignored. As noted earlier, the mortgaging of BI into CGs and vice versa is a possibility to which many commentators are potentially receptive. We cannot complete our discussion of streams and grants, therefore, until we have addressed this issue of convertibility. And if my above defence of an unconditional, non-timelimited and partial BI holds then rather than the hybrid schemes of A\&A and White we might conceive of hybridity in terms of the convertibility of BIs into

\footnotetext{
${ }^{7}$ A partial BI would invite occasional 'time-outs' or sabbaticals from the labour market. The longer White's time-limited BI becomes then the more the difference between it and partial BI reduces.
} 
CGs. (The convertibility of CGs into BI is also interesting but not one I am concerned with here.)

\section{Converting Streams into 'Pools ${ }^{8}$}

The subject of convertibility obviously requires questions and analyses relating to norms (what principles should guide convertibility?), economy and affordability (how much can the state allow to be converted at any one time?), administration (how would the convertibility process operate?) and transition (how would we get from here to there?). I am going to concentrate upon the normative, since the others demand that we propose a complete BI scheme, with details of costings, funding, management etc., that there is no room for here - though I will use some back-of-the-envelope figures for illustrative purposes. So, there are three main questions to be addressed in turn. When should convertibility be permitted? How much of one's stakeholder entitlement should be convertible? Should convertibility only be permitted for a proscribed range of activities?

Let me suggest that there are three obvious ages after which convertibility might be permitted: 18,22 and 30 . Since 18 years is the age at which most democracies allow the vote this might be thought of as a leading candidate. However, the fact that 18 is a threshold in one sense does not necessarily mean it should be so in another for two reasons. Firstly, the average 18 year old may not be mature enough. Of the rights activated at or by 18 some have relatively trivial consequences for the person concerned and where the consequences are less trivial many countries take steps to inhibit their impact, e.g. child-bearing at too young an age is not generally encouraged. Secondly, the average 18 year old already has too many pressures to cope with, especially in those societies where competition for qualifications, advancement and status is high. In short, since the transition from childhood to adulthood is gradual young adults require more paternalism than not-soyoung ones.

If 18 is a less attractive candidate than it appears at first what of 22? The rationale for nominating this age follows from the expectation that most school-leavers across developed nations will attend university so that convertibility at 22 years encompasses the normal age of graduation plus an extra year for further reflection upon what an income pool might be used for and what the long term effects of convertibility might be. Of course many individuals will not attend university but, nevertheless, it seems reasonable to require someone to move beyond their teenage years, into a period when maturity develops and decisions really begin to matter, before being able to access a considerable sum of money. If most people can make decisions by then with thought, care and a greater likelihood of success then it seems unwise to disallow convertibility.

But the fact that some convertibility may be permissible at 22 years does not necessarily mean that an entitlement to convert the permissible amount in full should apply from then. For just as A\&A spread the distribution of their grant out over several years, so the kind of paternalism I defended in my earlier critique might motivate us to exercise caution also. The 'alienation'

\footnotetext{
${ }^{8}$ I am here defining a 'pool' as a grant which has been specifically converted by the relevant individual out of the stream to which they are entitled.
} 
arguments cited against A\&A come back into play, namely that since a person's future self needs protection against their younger self (both after and before they reach 65), and since that person may only provide limited protection themselves, then there should be limits on convertibility. This argument can be applied across the lifecourse but applies particularly to a person in their 20s when life's waters are being tested. While we want our earliest steps to succeed we have to allow for the possibility that they will not or that we will simply wish to change course later and will be less able to do so if our stakeholder resources have been exhausted already.

What I therefore propose is a sliding scale of convertibility with a smaller percentage of future streams being convertible into pools between 22-30 years of age than after the age of 30. Since our 30s are the decade in which people are more likely to buy their first house, settle into a career and raise a family then it seems reasonable to assume that people can, on average, exercise greater self-control and self-awareness then than they can in their 20s. Equally, it seems reasonable to suggest because most life plans will have been initiated by the time someone is approaching retirement we should specify an upper limit on convertibility in order to encourage lump-sum investment during the decades when it can assist the most - I therefore agree with A\&A that a citizen's pension should be inalienable. However, all of this is unhelpfully abstract without some percentages and this requires consideration of how much of one's stakeholder entitlement should be convertible; the second of the three questions I wish to review.

We can perhaps specify some possible lower and upper limits easily enough. If the maximum amount we are permitted to convert from a stream into a pool is too low then the sum yielded will also be low and so less likely to be efficacious. If, on the other hand, the maximum is too high then the alienation objection becomes relevant once again. What this suggests is a maximum conversion of one's total stakeholder entitlement between the years of 22 and, say, 65 of somewhere between $5 \%$ and $30 \%$. Let me explain. Convertibility is not permissible below the age of 22 or above the (assumed retirement) age of 65 for reasons given above. We are therefore dealing with 43 years worth of stakeholding. Let us presume a modest income stream of $£ 60$ per week; this is a partial BI which (at almost $10 \%$ of UK average earnings before tax in 2007) does not provide enough for bare subsistence but is conceivably affordable and would either boost the income of employees - especially the lowest earners - or allow them extra free time without loss of income. This translates into a 43 year total of $£ 134,160$ per person. ${ }^{9}$ Converting $5 \%$ of this total stake or asset yields $£ 6708$, just enough to assist with the activities valued by defenders of grants: education, house-buying, etc.; a conversion of anything above $30 \%$ leaves a weekly BI of less than about $£ 42$ making it less able to realise the activities defended by its supporters, e.g. the culture of disposable time. So where within this range should the maximum be set?

So much depends upon the total sum to be distributed. I have assumed a very moderate sum that only just makes a BI defensible; if less than this can be afforded then we should either prefer a system of grants per se or at least a

\footnotetext{
${ }^{9}$ I am ignoring the question of how this sum would be funded, but this potentially affects the issue of how much convertibility is permitted that a longer analysis would have to accommodate. For example, if the income stream is entirely or partly an annuity then the issue of when the principal matures is obviously relevant.
} 
grants-system that constitutes a stage of gradual transition towards income streams. At the level I have assumed the weekly difference between $£ 60$ and, say, $£ 42$ is minimal for all but the lowest earners, perhaps implying that a $30 \%$ conversion itself is an acceptable maximum since the benefits (a pool of $£ 40,248$ plus a continued guaranteed income stream) outweigh the costs (a reduction in the income stream of $£ 18 \mathrm{pw}$ ). But if a higher BI were eventually introduced, perhaps something approaching $20 \%$ of average earnings, then the benefits of a BI are clearer and the conversion percentage could be reduced to $10-20 \%$ or so while still yielding significant pools. ${ }^{10}$

An added difficulty comes when we think about the sum's reduction according to age. The $£ 40 \mathrm{~K}$ maximum referred to above was, of course, $30 \%$ of the total income stream available over 43 years ( $£ 134 \mathrm{~K})$. If we allowed that to be the total sum convertible then the latest at which it could be made available would be 52 years. In other words, because a conversion yielding $£ 40 \mathrm{~K}$ represents 671 weeks (12.9 years) of a $£ 60$ weekly BI then it represents the total remaining income stream available to someone at age 52 , or 13 years before entitlement to the citizen's pension commences. A conversion at that point would leave that person without a guaranteed income for the next 13 years, then. Doing so would seem to reinvoke issues of paternalism and inalienability which I invoked when arguing against Ackerman and Alstott (1999, pp. 39-41). Therefore, if leaving someone without an income stream is ruled out (since in many cases that $£ 40 \mathrm{~K}$ investment will not succeed) this implies that the $30 \%$ maximum should always be $30 \%$ of the total remaining stake. In short, the longer a person leaves converting their income stream into a pool the smaller the sum thus yielded - so in reality the $30 \%$ maximum will represent much less than $£ 40 \mathrm{~K}$. This is another reason why those in their $20 \mathrm{~s}$ should have fewer entitlements to convert than someone later in life - since the temptation to yield and misuse something close to $£ 40 \mathrm{~K}$ would be too high for many; as the total income stream left available diminishes then conversion becomes less attractive as people enter their 50s. We would therefore envisage most conversions occurring when individuals are in their 30 s and 40s.

Finally, should convertibility only be permitted for a proscribed range of activities? While streams can be diverted into pools should we allow anyone, for any reason, to dip their feet in the water? An obvious potential danger with allowing laissez faire conversions is that this could encourage criminal activity and so we might disqualify those with a record of committing at least certain forms of crime (especially related to violence, theft and drugs) from converting their income stream. We might go further, of course, and deny such ex-criminals the stream itself, making income support conditional for a certain period of time at least. However, in the event of successful rehabilitation unconditionality might be reactivated as a final part of social reintegration. The same principle might therefore apply to convertibility. Criminal conviction disqualifies this right for a certain period after release from jail but not necessarily forever.

But what of the more fundamental objection, that convertibility should be restricted to certain activities? It is not against the law to go on a world cruise but should someone be able to trade in part of their future security, and spend

\footnotetext{
${ }^{10}$ All of this being dependent upon the conversion process not creating adverse inflationary pressures, of course.
} 
a significant sum of society's resources, doing so? For some the cruise will represent simple leisure, for others it would represent a form of personal development. Either way, many will be uncomfortable with streams being converted into pools for this purpose. As such, at least in its early stages, we might prefer to link the converted pool with White's proposal for a development grant, with all of its relevant advantages (it encourages responsible investment) but also the disadvantages identified above (bureaucratic complexity and cost, productivist restrictions). Alternatively, if we think that individuals should be able to convert their stream into a pool for whatever purposes they think best, for while some people will want a world cruise others will want sabbaticals to write their novel, volunteer full time or dedicate themselves to their child's formative years, then that means challenging the productivist assumptions of social policies and popular attitudes. Should we be so scared of people choosing leisure that we eliminate opportunities for valuable but not necessarily productive activities as well?

There is no point in being naïve here and imagining that this would be an easy sell. Yet I suspect that the work ethic is less restrictive and inflexible than governments suppose - or else they would not spend so much time enforcing an ethic that they otherwise assume to be universally ingrained within us. Because the meaning and scope of the work ethic has changed in the past it would be equally naïve to imagine it as some kind of homogenous convention immune from change in the future too. Therefore, since many of us are attracted to BI and CG debates because they present the opportunity to combine pragmatism with utopianism, a compromise would be to design convertibility criteria along the lines suggested by White's development grant scheme while allowing for the possibility of loosening and liberalising those criteria over time if and when social attitudes change. For if we are not here to affect social attitudes then I am unsure what the point of these debates even is.

\section{Conclusion}

I have attempted to intervene in some recent debates concerning streams and grants. Both approaches to asset-based welfare and stakeholding attempt to move beyond social policy's traditional concern with social insurance and means-testing but they nevertheless diverge on whether resources should be distributed continuously or in lump-sums. I argued that when considering not only the meaning of but also the operation of concepts like freedom and security it is worth emphasising what these proposals hold in common. Real differences of opinion are visible and indeed inevitable, though, and I tried to move the debate on via a defence of income streams based upon the principles of freedom and security. I then reviewed some normative questions concerning the convertibility of streams into pools, arguing there is scope here for a rapprochement with certain CG schemes (specifically White's development grants) which should motivate the pragmatist and utopian within us all.

\section{References}


Ackerman, B. and Alstott, A. (1999) The Stakeholder Society. Yale: Yale University Press.

Ackerman, B. and Alstott, A. (2004) "Why Stakeholding?" Politics and Society 32 (1), pp. 41-60.

Ackerman, B. (2003) "Radical Liberalism," in Dowding, K., De Wispelaere, J. and White, S. (eds.) The Ethics of Stakeholding. Basingstoke: Palgrave.

Arneson, R. (2003) "Should Surfers be Fed?" in Reeve, A. and Williams, A. (eds.) Real Libertarianism Assessed. Basingstoke: Palgrave.

Beck, U. (2000) The Brave New World of Work. Cambridge: Polity.

DeWispelaere, J. and Stirton, L. (2004) "The Many Faces of Universal Basic Income," Political Quarterly 75 (3), pp. 266-274.

Dowding, K., De Wispelaere, J. and White, S. (2003) "Stakeholding - a New Paradigm in Social Policy?" in Dowding, K., De Wispelaere, J. and White, S. (eds.) The Ethics of Stakeholding. Basingstoke: Palgrave.

Fabre, C. (2003) "The Stake: An Egalitarian Proposal?" in Dowding, K., De Wispelaere, J. and White, S. (eds.) The Ethics of Stakeholding. Basingstoke: Palgrave.

Fitzpatrick, T. (1999) Freedom and Security. Basingstoke: Macmillan.

Fitzpatrick, T. (2005) "The Fourth Attempt to Construct a Politics of Welfare Obligations," Policy \& Politics 33, pp. 3-21.

Goodin, R. (1992) "Towards a Minimally Presumptuous Social Welfare Policy," in Van Parijs (ed.) Arguing for Basic Income. London: Verso.

Goodin, R. (2002) "Permissible Paternalism," in LaFollette, H. (ed.) Ethics in Practice. $2^{\text {nd }}$ ed., Oxford: Blackwell.

LeGrand, J. (2003) Motivation, Agency and Public Policy. Oxford: Oxford University Press.

Nissan, D. \& LeGrand, J. (2000) A Capital Idea. London: Fabian Society.

Nussbaum, M. (2006) Frontiers of Justice. Harvard: Belknap Press.

Pateman, C. (2004) "Democratising Citizenship," Politics and Society 32 (1), pp. 89-105.

van der Veen, R. (2003) "Assessing the Unconditional Stake," in Dowding, K., De Wispelaere, J. and White, S. (eds.) The Ethics of Stakeholding. Basingstoke: Palgrave.

Van Parijs, P. (1995) Real Freedom for All. Oxford: Oxford University Press.

Van Parijs, P. (2003) "Hybrid Justice, Patriotism and Democracy," in Reeve, A. and Williams, A. (eds.) Real Libertarianism Assessed. Basingstoke: Palgrave.

Van Parijs, P. (2004) "Basic Income: A Simple and Powerful Idea for the Twentyfirst Century," Politics and Society 32 (1), pp. 7-39.

Van Parijs, P. (2006) "Basic Income Versus Stakeholder Grants," in Wright, E. (ed.) Redesigning Distribution. London: Verso.

Walzer, M. (2004) Politics and Passion. Yale: Yale University Press.

White, S. (2003a) The Civic Minimum. Oxford: Oxford University Press.

White, S. (2003b) "Freedom, Reciprocity and the Citizen's Stake," in Dowding, K., De Wispelaere, J. and White, S. (eds.) The Ethics of Stakeholding. Basingstoke: Palgrave.

White, S. (2004) "Markets, Time and Citizenship," Renewal 12 (3), pp. 50-63.

White, S. (2007) Equality. Cambridge: Polity.

Wright, E. O. (2004) "Basic Income, Stakeholder Grants and Class Analysis," Politics and Society 32 (1), pp. 79-87.

Wright, E. (ed.) (2006) Redesigning Distribution. London: Verso. 